\title{
Polymer-polymer miscibility in PEO/cationic starch and PEO/hydrophobic starch blends
}

\author{
A. G. B. Pereira ${ }^{*}$, A. T. Paulino 2 , A. F. Rubira1, E. C. Muniz ${ }^{1}$ \\ ${ }^{1}$ Grupo de Materiais Poliméricos e Compósitos, GMPC - Departamento de Química Universidade Estadual de Maringá - \\ Av. Colombo 5790 - 87020-900, Maringá, Paraná, Brazil \\ 2Departamento de Engenharia de Sistemas Químicos - Faculdade de Engenharia Química. Universidade Estadual de \\ Campinas - Av. Albert Einstein 500, Campinas, São Paulo, Brazil
}

Received 18 January 2010; accepted in revised form 22 March 2010

\begin{abstract}
The main purposes were evaluating the influence of different starches on the miscibility with Poly(ethylene oxide) (PEO) and their effects on the spherulite growth rate. Polymer-polymer miscibility in PEO/cationic starch and $\mathrm{PEO} /$ hydrophobic starch blends consisting of different w/w ratios (100/0, 95/05, 90/10, 80/20, 70/30, 65/35 and 60/40) was investigated. This analysis was based on the depression in the equilibrium melting temperature $\left(T_{m}^{0}\right)$. By treating the data of thermal analysis (Differential Scanning Calorimetry - DSC) with Nishi-Wang equation, a positive value (0.68) was found for the interaction parameter of PEO/cationic starch. For PEO/hydrophobic starch blends, a negative value $(-0.63)$ was obtained for the interaction parameter. The results suggested that PEO/cationic starch system should be immiscible. However, the system PEO/hydrophobic starch was considered to be miscible in the whole range of studied compositions. Through optical microscopy analysis, it was concluded that the spherulite growth rate is significantly affected by changing the amount and the type of starch as well.
\end{abstract}

Keywords: polymer blends and alloys, PEO/starch blends, PEO/starch miscibility, PEO/starch spherulite growth rate, biopolymer

\section{Introduction}

Blending of polymers is an interesting route for producing new materials, basically due to economics aspects [1]. The miscibility between the polymers is a very important factor in the development of polymer blends $[1,2]$. Considering the low entropy associated to the polymers mixture, $\Delta S_{m}$, the miscibility between the components of a polymer blend is mainly driven by the enthalpy of mixing, $\Delta H_{m}$. Thus, effects that decrease $\Delta H_{m}$ will favor to the miscibility due to the decrease of the Gibbs energy of mixture, $\Delta G_{m}$. In the light of this, attractive interactions among side groups or polymer segments are, in most of the cases, responsible for polymer-polymer miscibility.
Different techniques have been used for evaluating the miscibility, for example, thermal analysis through determination of the glass transition temperature $\left(T_{g}\right)$ [3-5], microscopy (Optical Microscopy - OM, Scanning Electronic Microscopy - SEM, Atomic Force Microscopy - AFM, Transmission Electronic Microscopy - TEM, and so on) [5-8] and spectroscopy (Fourier Transform Infrared FTIR-Image, Raman-Image, Nuclear Magnetic Resonance - NMR, and so on) [9-12].

The presence of an amorphous (or slightly crystalline) component affects the crystallization process of the other polymer component significantly. When a given system is miscible, the equilibrium melting temperature $\left(T_{m}^{0}\right)$ is expected to be lower 
than that for the pure crystallizable component. $T_{m}^{0}$ is the melting temperature for a perfect crystal when it presents same chemical potential of the surrounding liquid phase. The mixing of an amorphous (or slightly crystalline) polymer with a highly crystallizable one forming a polymer blend allows the new chemical potential of the liquid phase to be lower than that of the crystalline phase and, therefore, the equality of the chemical potentials of the liquid and the crystalline phases will be settled at lower temperature [13]. In this way, when the polymer blend consists of a crystallizable polymer and an amorphous polymer, the depression in equilibrium melting temperature $\left(T_{m}^{0}\right)$ may be used for evaluating the polymer-polymer interaction parameter $\left(\chi_{12}\right)$ and thus the system miscibility [14].

Starch is a polysaccharide constituted by portions of amylose (linear) and amylopectin (branched) usually in a ratio of $20 \%: 80 \%$, respectively [15, 16]. Often, it comes from vegetables such as cassava, corn, wheat, among others. Taking into account its interesting properties such as biodegradability [17, 18], biocompatibility [19], availability and low costs [18], starch has been extensively studied as drug delivery system [20-22], cell culture scaffolds in tissue engineering [23, 24], papermakers [25], adhesives [26], polymer blends and composites [27-29], and others. In general, chemical modifications (grafting) and physical mixture (blending) [30] are some strategies employed in order to overcome limitations such as immiscibility with unlike polymers, unsatisfactory mechanical properties and degradation at low temperature [31]. Poly(ethylene oxide) (PEO), a semi-crystalline synthetic polymer, has the general molecular structure $\left(\mathrm{CH}_{2} \mathrm{CH}_{2} \mathrm{O}\right)_{n}$. Due to its biocompatibility and low toxicity, the FDA has approved its use in many biomedical devices [32], including drug delivery systems [33, 34], tissue replacement and scaffolds [35-37], and surface coatings for the inhibition of protein and/or cell adsorption [38-41].

$\mathrm{PEO} /$ starch blends present great potential applications mainly in the biomedical field, like scaffolds for cell culture and tissue engineering [42-44]. This work is devoted to investigate the miscibility and crystallization rates of starches (cationic and hydrophobic) with PEO in different weight ratios and crystallization temperatures. Differential scanning calorimetry (DSC) was applied to evaluate the
$T_{m}^{0}$ values and thermal behavior of system, by considering the miscibility as response. The spherulites growth rates were analyzed by the use of an optical polarized microscopy. The determination of miscibility was based on the evaluation of equilibrium melting point depression through the Nishi-Wang equation [14].

\section{Experimental}

\subsection{Materials}

PEO (Aldrich 18,199-4, $M_{v}: 200 \mathrm{~kg} / \mathrm{mol}$ ). Hydrophobic starch, 9.4 mol\% ethyl groups substituted on hydroxyl. Cationic starch, $5.8 \mathrm{~mol} \%$ with quaternary ammonium salts substituted on hydroxyl. The modified starches are commercial samples gently donated by Lorenz Company (Cianorte, Brazil). The unmodified starch was donated by Impal S.A. (São Tomé, Brazil). All reagents were used without further purification. ${ }^{1} \mathrm{H}$ NMR was used for the determination of the degree of substitution on both modified starches. The value of molar mass of cationic starch is $12 \cdot 10^{3} \mathrm{~kg} \cdot \mathrm{mol}^{-1}$, hydrophobic starch is $3.7 \cdot 10^{3} \mathrm{~kg} \cdot \mathrm{mol}^{-1}$, and the unmodified starch is $5.4 \cdot 10^{3} \mathrm{~kg} \cdot \mathrm{mol}^{-1}$, determined by Gel permeation chromatography/Size exclusion chromatrography (GPC/SEC) as described in the next section.

\subsection{Sample preparation}

Films of $\mathrm{PEO}$ and $\mathrm{PEO} / \mathrm{starch}$ blends at w/w ratios of $95 / 05 ; 90 / 10 ; 80 / 20 ; 70 / 30 ; 65 / 35$; and $60 / 40$ were obtained as follows: for each blend ratio the desired amount of starch was solubilized in distilled water at $80^{\circ} \mathrm{C}$, after the cooling of the starch solution the needed quantity of PEO was added to form a final aqueous solution of $5 \% \mathrm{w} / \mathrm{v}$. Then, films of the different blends were obtained by casting at room temperature. The films were dried for 3 days (ambient conditions, $\sim 25^{\circ} \mathrm{C}, 1 \mathrm{~atm}$ ) followed by $24 \mathrm{~h}$ under vacuum at room temperature (ca. $25^{\circ} \mathrm{C}$ ). The thicknesses of films were around $120 \mu \mathrm{m}$.

\subsection{Crystallization of pure PEO and PEO/starch blends}

The samples were crystallized in the absence of light and under reduced pressure in an aluminum 
oven specially constructed for this purpose. The temperature of the system was controlled by a thermo-bath with $\pm 0.1^{\circ} \mathrm{C}$ of precision. The samples (PEO and blends) were heated up to the molten state $\left(\sim 70^{\circ} \mathrm{C}\right)$ and kept at this temperature for $5 \mathrm{~min}$ to erase the thermal history. Then, the samples were quickly cooled to a desired crystallization temperature, $T_{C}$, and left at that temperature for $1 \mathrm{~h}$. Each sample was crystallized with $T_{C}$ ranging from 42 to $60^{\circ} \mathrm{C}$. The $T_{C}$ was increased in steps of $3^{\circ} \mathrm{C}$.

\subsection{DSC analysis}

The DSC analysis was carried out in a calorimeter (Shimadzu, Model DSC 50, Japan) at a heating rate of $10^{\circ} \mathrm{C} \cdot \mathrm{min}^{-1}$ under a nitrogen stream of $10 \mathrm{ml} \cdot \mathrm{min}^{-1}$. For the pure PEO and a fixed blend ratio, the DSC curve was run after the sample has been treated at a desired $T_{C}$ for $1 \mathrm{~h}$. The value of melting point temperature, $T_{m}$, was estimated from melting peak, by applying the first derivative method. For the pure PEO and for each PEO/starch blend, the equilibrium melting temperature $\left(T_{m}^{0}\right)$ was evaluated by using the Hoffman-Weeks plots [45], and the miscibility of the system was accessed based on the interaction parameter value $\left(\chi_{12}\right)$, which was evaluated by applying the Nishi-Wang equation [14].

\subsection{Spherulites growth rate}

The spherulites growth rates of pure PEO and $\mathrm{PEO} /$ starch blends were measured by the use of a polarized optical microscope equipped with a digital camera connected to a computer. Then, realtime images of crystallizing-events were recorded. The temperature of the sample $\left(T_{C}\right)$ was controlled by a hot-stage (Micro-Química, model MQSDCT3 , Brazil) coupled to the microscope. For a given crystal growing at fixed $T_{C}$, the spherulite sizes were calculated, as a function of crystallization time, directly from the stored images, using a screen monitor. PEO spherulites growth rates were obtained from the linear dependence of spherulite size as a function of time at a fixed $T_{C}$. Triplicates were made for each blend at each $T_{C}$.

\subsection{Evaluation of the molar mass of starch by GPC/SEC}

Aqueous solutions of starch $(0.5 \mathrm{w} / \mathrm{v} \%)$ were prepared under $24 \mathrm{~h}$ of stirring of at $80^{\circ} \mathrm{C}$. After, the solutions were diluted with distilled water until a final concentration of $0.25(\mathrm{w} / \mathrm{v} \%)$ and then filtered using cotton.

The molar masses of the starches were determined by gel permeation chromatography (GPC, some times also referred to as size exclusion chromatography, SEC) technique using equipment from Varian Inc. Scientific Instruments (USA) at room temperature and a Linear Ultrahydrogel $(7.8 \mathrm{~mm} \times$ $300 \mathrm{~mm}$ ) chromatographic column and a flow rate of $0.5 \mathrm{ml} \cdot \mathrm{min}^{-1}$. Differential refractometer was used as detector. Pullulan with molar masses ranging from 1 to $100 \mathrm{~kg} \cdot \mathrm{mol}^{-1}$ were used as references while $\mathrm{NaNO}_{3}\left(0.1 \mathrm{~mol} \cdot \mathrm{l}^{-1}\right)$ was used as eluent for building the calibration curve. Straight line dependence of molar mass $(M)$ as a function of elution volume was obtained, fitted by the Equation (1):

$\log (M)=-0.9273 V_{e}+12.55$

where $M$ is the averaged $M_{n}$ of the standard Pullulan, and $V_{e}$ is the eluted volume.

\subsection{Characterization of the cationic and the hydrophobic starches by FTIR, ${ }^{1}$ HNMR, ${ }^{13} \mathrm{CNMR}$ and wide angle $\mathrm{X}$-ray scattering (WAXS)}

The characterization of the commercial samples of starches was performed by the use of FTIR, NMR spectroscopies and WAXS.

Fourier-transform infrared (FTIR) spectrum of each type of starch was obtained from a FTIR spectrophotometer (Bomem, model MB-100, Canada). The powder polymer was compressed with $\mathrm{KBr}$ powder into a tablet sample before the analysis. The spectra were obtained in the wave number range of 400-4000 $\mathrm{cm}^{-1}$ with resolution of $2 \mathrm{~cm}^{-1}$ by collecting 64 scans.

${ }^{1} \mathrm{H}$ and ${ }^{13} \mathrm{C}$ NMR spectra were obtained through a $300 \mathrm{MHz}$ Varian model Mercury Plus BB spectrometer (USA) using DMSO- $d 6$ as solvent (10\% wt.v). 
Wide-angle X-ray (WAXS) diffraction patterns were obtained using a SHIMADZU XRD-6000 diffractometer (Japan) $\left(40 \mathrm{kV}, 30 \mathrm{~mA}, \mathrm{CuK}_{\alpha}\right)$ in the diffraction angle $(2 \theta)$ ranging from 3 to $60^{\circ}$ at a rate of $3^{\circ} \cdot \mathrm{min}^{-1}$.

\section{Results and discussion}

Miscibility results of PEO/unmodified starch system using the depression of $T_{m}^{0}$ through the NishiWang equation were recently published by our group [46]. So, comparative discussion of the results of this work with those with $\mathrm{PEO/unmodi-}$ fied starch will be done in the following sections.

\subsection{Characterization of the cationic and the hydrophobic starches}

In order to verify the effects of side groups on cationic and the hydrophobic starches introduced through industrial process (due to being commercial samples) on different properties investigated in this work, FTIR, ${ }^{1} \mathrm{H}$ and ${ }^{13} \mathrm{C}$ NMR spectra and WAXS profiles of such modified starches were obtained and compared to the respective unmodified starch, for the sake of comparison.

The chemical modification of starch generally occurs by the grafting of functional groups, mainly by the substitution of the hydrogen atom of the hydroxyl groups [47]. For the preparation of

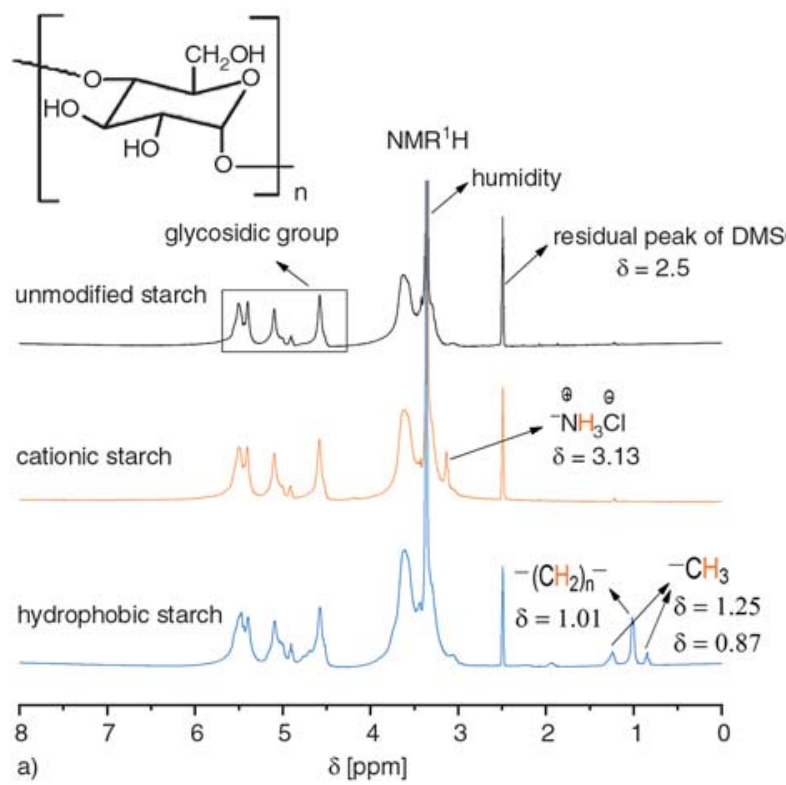

cationic starch, a common way is by the introduction of ammonium salts in the backbone of starch [48]. In the case of hydrophobic starch, the groups to be grafted to the starch chain are normally hydrocarbon chains [49].

Figure 1 shows the FTIR spectra obtained for cationic, hydrophobic and unmodified starches. The spectra presented almost the same profile. The characteristic vibrational modes that appear at 1451,1121 and $1017 \mathrm{~cm}^{-1}$ were attributed to $\mathrm{C}-\mathrm{O}$ stretching of the unhydroglucose units. A broad band at $3414 \mathrm{~cm}^{-1}$ was attributed to $\mathrm{O}-\mathrm{H}$ vibration. The band at $2926 \mathrm{~cm}^{-1}$ is typical of $\mathrm{C}-\mathrm{H}$ vibration. The more significant difference among them is related to the hydrophobic starch, in which the $\mathrm{C}-\mathrm{O}-\mathrm{C}$ and $\mathrm{C}-\mathrm{O}-\mathrm{H}$ vibrational mode (in the range

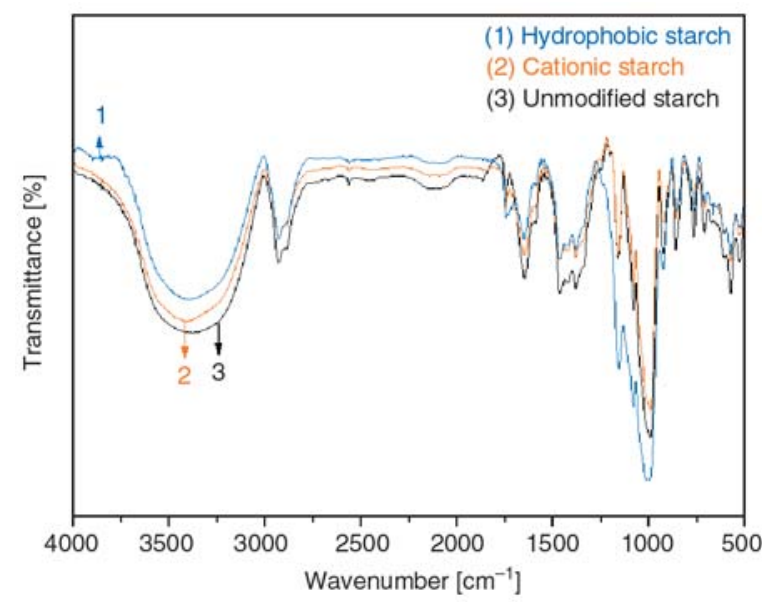

Figure 1. FTIR spectra for unmodified, cationic and hydrophobic starches

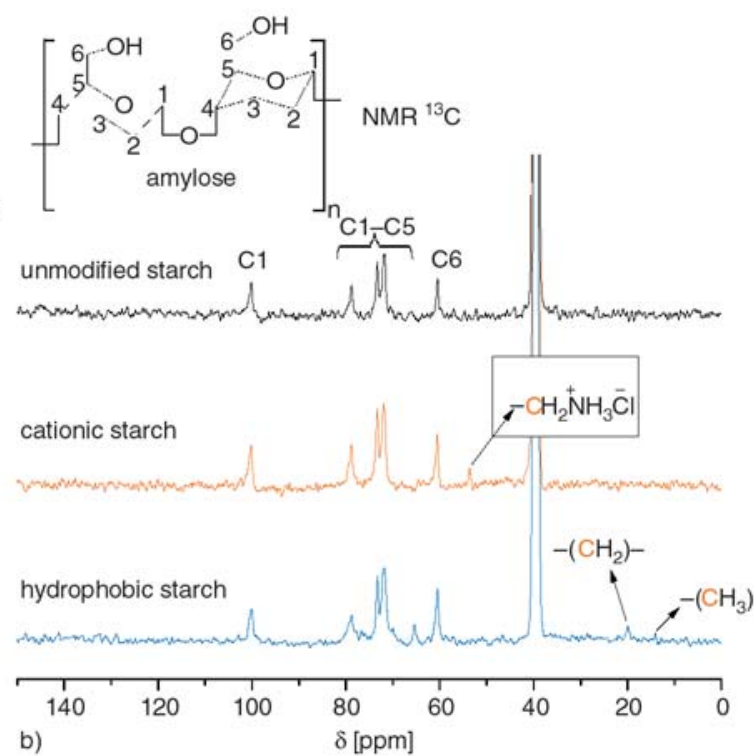

Figure 2. Nuclear Resonance magnetic of unmodified starch, cationic starch and hydrophobic starch a) ${ }^{1} \mathrm{H}$ NMR and b) ${ }^{13} \mathrm{C}$ NMR 
of $1300-950 \mathrm{~cm}^{-1}$ ) presented a higher intensity compared to the other starches.

${ }^{1} \mathrm{H}$ and ${ }^{13} \mathrm{C}$ NMR spectra obtained from starches (unmodified, cationic and hydrophobic) are presented in Figure $2 a$ and $2 b$, respectively. From those spectra it is possible to point out that the starches are chemically different. The presence of the peak at $\delta=3.13$ on the ${ }^{1} \mathrm{H}$ NMR cationic starch spectrum was observed. Such signal was assigned to hydrogen atoms bonded to nitrogen atom, confirming the presence of ammonium salt on the polymer chains of cationic starch. It was also confirmed by the presence of the ${ }^{13} \mathrm{C}$ peak at ca. $\delta=52$ which was attributed to carbon atom bonded to nitrogen.

In the case of hydrophobic starch, the signals on ${ }^{1} \mathrm{H}$ NMR spectrum at $\delta=1.01\left(-\mathrm{CH}_{2}-\right), \delta=1.25$ and $\delta=0.87\left(-\mathrm{CH}_{3}\right)$ indicate the presence of hydrocarbon side groups in the starch polymer chains that was also confirmed by the ${ }^{13} \mathrm{C}$ peaks at ca. $\delta=12.5$ and $\delta=20$ attributed to $-\mathrm{CH}_{2}-$ and $-\mathrm{CH}_{3}$ groups. Nevertheless, the hydrocarbon chains should not be longer, due the fact that the integration of those peaks is very small in relation to the other peaks.

Although the NMR analysis showed the chemical groups grafted in the both cationic and hydrophobic starch chains, such fact is not clear in the FTIR spectra, suggesting that the degree of modification should be low, as confirmed by the calculus of modification from the ${ }^{1} \mathrm{H}$ NMR spectra.

Figure 3 presents the WAXS patterns for modified and unmodified starches. It is appropriate to notice that those starches do not present any well resolved peak; otherwise the curves are in halo form, suggesting that the starches comprise structure with a very low degree of crystallinity, and for that reason in this work they were considered as amorphous.

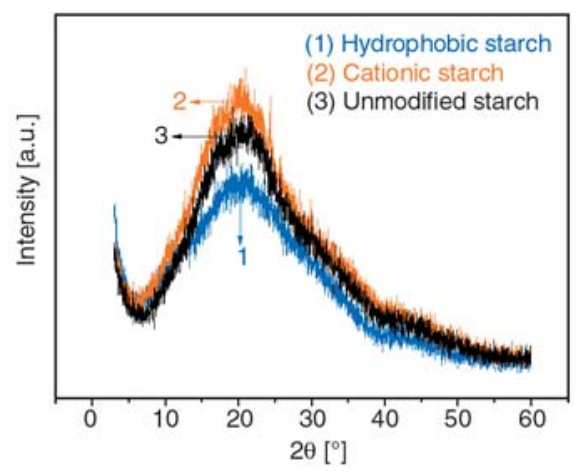

Figure 3. WAXS patterns for different starches (unmodified, cationic and hydrophobic)

\subsection{Thermal analysis from DSC data}

Thermograms were obtained for pure PEO and for several $\mathrm{PEO} /$ starch blends after being crystallized at given crystallization temperatures $\left(T_{C}\right.$, ranging from 42 to $60^{\circ} \mathrm{C}$ ). The non-equilibrium melting temperature value $\left(T_{m}\right)$ was determined through the inflection point of the first derivative of the melting peak, as previously discussed [46].

According to Hoffman and Weeks approach [14, 45,50 ], the melting temperature of an ensemble of crystals that: i) is large enough to neglect surface effects; ii) is in equilibrium with the liquid phase; and iii) presents perfection degree of crystallinity consistent with the minimum free energy, is defined as equilibrium melting temperature, $T_{m}^{0}$. Due to the high molar mass of polymers, their crystals are, in general, small and also display elevated density of defects. In this sense, the crystallization temperature $\left(T_{C}\right)$ has a great influence on $T_{m}$, which one commonly is lower than $T_{m}^{0}$.

After all the DSC runs for pure PEO and for a given the PEO/Starch blends were accomplished, the respective $T_{m}^{0}$ values were evaluated through the Hoffman-Weeks method [45] as showed in Figure 4, by applying the Equation (2):

$$
T_{m}=\left(\frac{1}{\eta}\right) T_{C}+T_{m}^{0}\left(1-\frac{1}{\eta}\right)
$$

where $T_{m}$ is the non-equilibrium melting temperature, $\eta$ is the lamellar thickness factor, which is the ratio of the lamellar thickness to the critical nucleus thickness in the crystallization process [45]. This equation means that the crystallization temperature $\left(T_{C}\right)$ affects the melting point $\left(T_{m}\right)$ of a polymer, mainly attributed to the dependence of polymer chains mobility on the temperature [50].

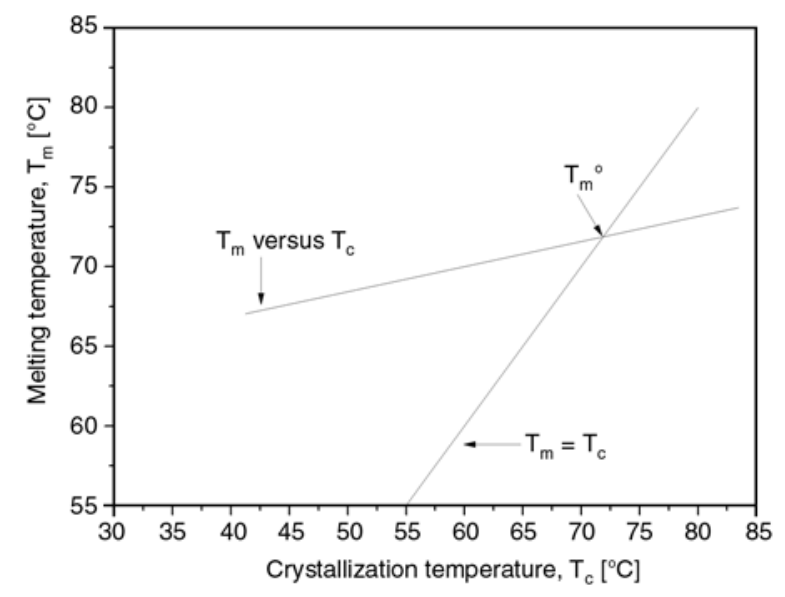

Figure 4. The equilibrium melting temperature $\left(T_{m}^{0}\right)$ determination 
As described in the introductory section, the depression in $T_{m}^{0}$ has been widely used to evaluate the miscibility of a polymer pair consisting of an amorphous and a crystalline component. Nishi and Wang [14] depicted the decrease of the $T_{m}^{0}$ in a crystalline polymer due to the presence of an amorphous miscible component and such depression can be predicted in through the Equation (3):

$$
\begin{aligned}
& \frac{1}{T_{m_{P E O}}^{0}}-\frac{1}{T_{m_{\text {Blend }}}^{0}}=\frac{R V_{P E O}^{u}}{V_{\text {starch }}^{u} \Delta H_{P E O}^{u}} . \\
& {\left[\frac{\ln \phi_{P E O}}{m_{P E O}}+\left(\frac{1}{m_{P E O}}-\frac{1}{m_{\text {starch }}}\right) \phi_{\text {starch }}+\chi_{P E O, \text { starch }} \phi_{\text {starch }}^{2}\right]}
\end{aligned}
$$

where $V_{i}^{u}$ is the molar volume of the repeating unit of the polymer; $\Delta H_{P E O}^{u}$ is the melting enthalpy of fully crystalline PEO; $\phi$ is the volume fraction; $\chi_{12}$ is the polymer-polymer interaction parameter; and $m_{i}$ is the average-number of repeating unit of $i$ component. The first and second terms (inside brackets) on the right side of equation refer to the entropy of mixing contribution for the decreasing of the equilibrium melting temperature, while the third term refers to the enthalpy share. Regarding macromolecules with high molar mass, the effect of the entropy is not remarkable and the depression in the melting temperature will be mainly of enthalpic nature, then the Equation (3) reduces into Equation (4):

$$
\begin{aligned}
& \frac{1}{T_{m_{P E O}}^{0}}-\frac{1}{T_{m_{\text {Blend }}}^{0}}= \\
& \left(\frac{R V_{P E O}^{u}}{V_{\text {starch }}^{u} \Delta H_{P E O}^{U}}\right) \chi_{P E O \text {,starch }} \phi_{\text {starch }}^{2}
\end{aligned}
$$

Based on Flory-Huggins theory, it can be shown that negatives values for the $\chi_{12}$ are correlated to existence of interactions between the polymers, thus resulting in the miscibility of the system.

So, after determination of the $T_{m}^{0}$ values for the blends, the evaluation of polymer-polymer interaction parameter and, consequently, the miscibility of the system were performed through the NishiWang equation (Equation (4).

Figures 5 and 6 show the dependence of $1 / T_{m_{P E O}}^{0}-1 / T_{m_{\text {Blend }}}^{0}$ to $\phi_{\text {starch }}^{2}$ for $\mathrm{PEO} /$ cationic starch and PEO/hydrophobic starch blends, respectively. The slope of the curve is related to the value of $\chi_{12}$. Also, negative slope means that $\chi_{12}$ is nega-

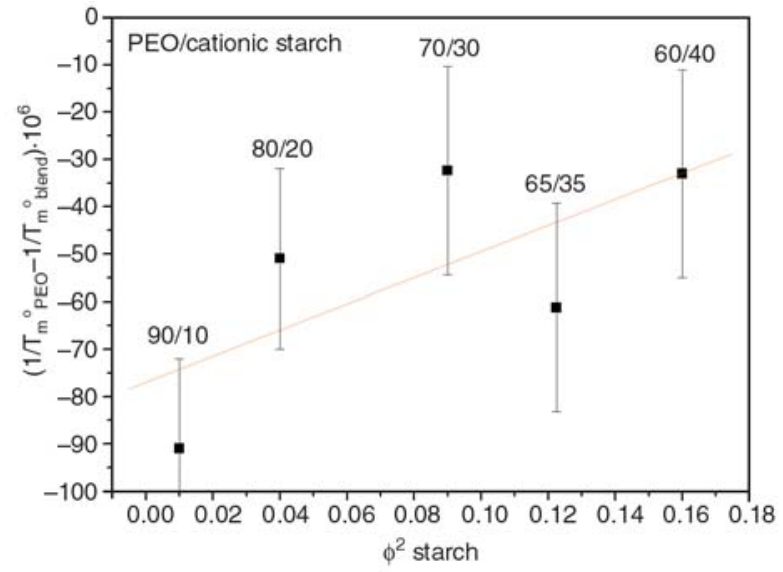

Figure 5. Dependence of $1 / T_{m_{P E O}}^{0}-1 / T_{m_{\text {Blend }}}^{0}$ with $\phi_{\text {starch }}^{2}$ for $\mathrm{PEO} /$ cationic starch blends

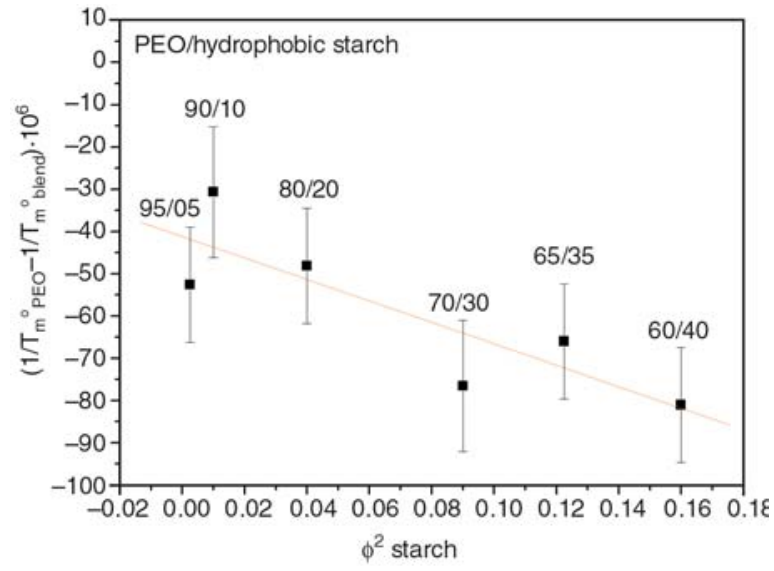

Figure 6. Dependence of $1 / T_{m_{P E O}}^{0}-1 / T_{m_{\text {Blend }}}^{0}$ with $\phi_{\text {starch }}^{2}$ for PEO/hydrophobic starch blends

tive-valued, then the system should be miscible. On the other hand, positive slope leads to positive values for $\chi_{12}$ suggesting immiscibility [51].

For PEO/cationic starch, the interaction parameter $\chi_{12}$ was determined as being 0.68 . The following values were used for such evaluation:

$$
\begin{aligned}
& R=8.314 \mathrm{~J} \cdot \mathrm{K}^{-1} \cdot \mathrm{mol}^{-1}, \\
& \Delta H_{P E O}=7.6 \mathrm{~J} \cdot \mathrm{K}^{-1} \cdot \mathrm{mol}^{-1}, \\
& \Delta H_{P E O}^{u}=40.3 \cdot 10^{-6} \mathrm{~m}^{3} \cdot \mathrm{mol}^{-1} \text { and } \\
& V_{\text {starch }}^{u}=104.7 \cdot 10^{-6} \mathrm{~m}^{3} \cdot \mathrm{mol}^{-1}
\end{aligned}
$$

obtained from the density $1.5 \cdot 10^{3} \mathrm{Kg} \cdot \mathrm{m}^{-3}$ [52]. The blend ratio at 95/05 was not used for such to evaluating, due to the fact that there was an increase in $T_{m}$, when compared to the pure PEO. The positive value for $\chi_{12}$ indicated a complete immiscibility of the polymers.

In spite of the existence of errors associated to the measurement from Figure 6 in the same extension from Figure 5, the interaction parameter for PEO/ hydrophobic starch was negative $\chi_{12}=-0.63$, indi- 
cating that the system is miscible in the whole range of studied compositions.

According to the Nishi-Wang equation, $\chi_{12}$ should be independent of composition or of morphology upon determination of $T_{m}^{0}[14,53]$. This implies that the equation concerned could not completely fit the experimental data and the occurrence the intercept far from the origin has been reported [54]. Although the starches present only a low degree of modification, it seems that it is enough to induce difference on miscibility behavior with starch/PEO blends. Besides, an important factor that might have contributed to those behaviors is the different molar masses (not deeply studied in this work).

It is known the effect of the solvent on the miscibility of a polymer pair. For instance, PMMA/PVAc is miscible in chloroform at $30^{\circ} \mathrm{C}$ whereas in DMF, at the same temperature, the blend is immiscible [55].

Regarding PEO/starch blends, they were prepared by casting from aqueous solution. In the case of samples containing cationic starch the interaction water/starch should be favorable in relation to $\mathrm{PEO} /$ starch considering the high dielectric constant

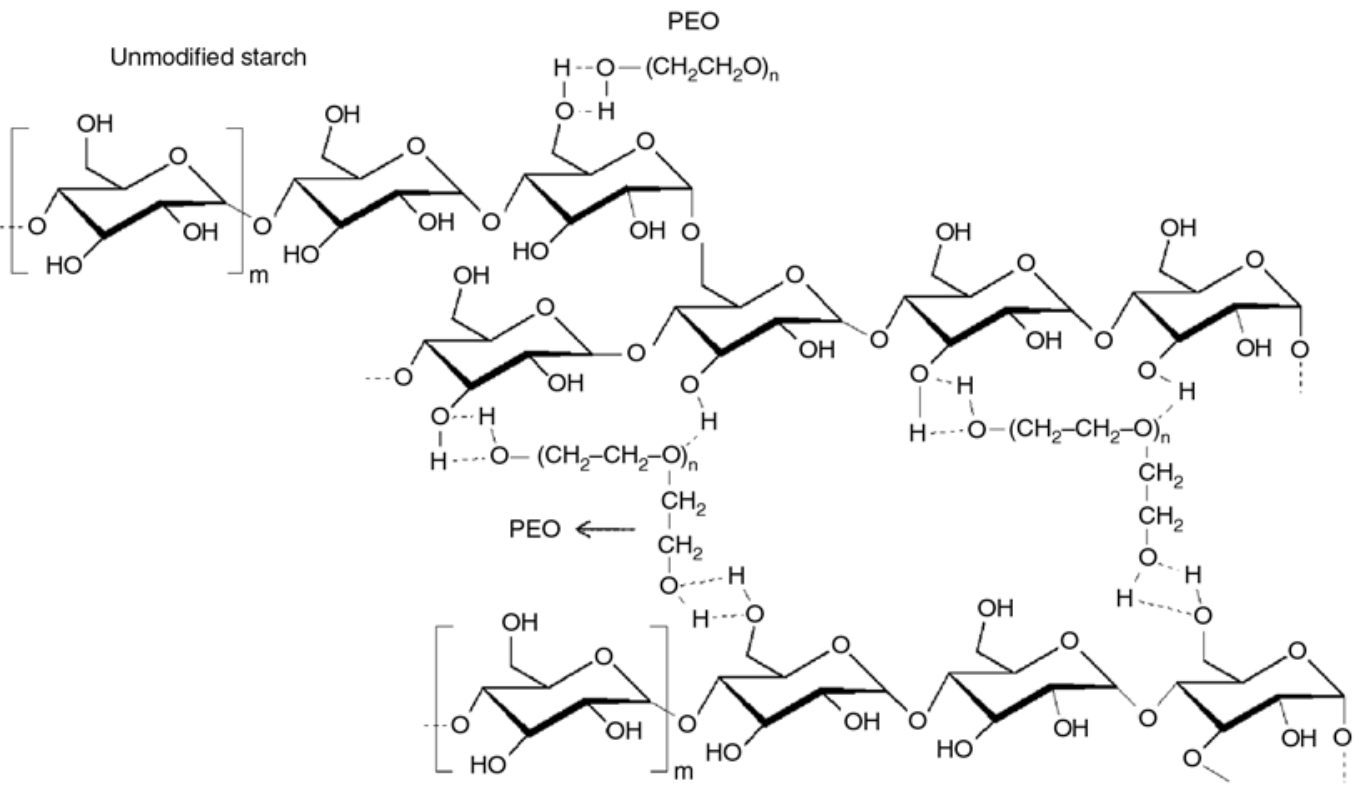

Figure 7. Possible interactions in unmodified starch/PEO

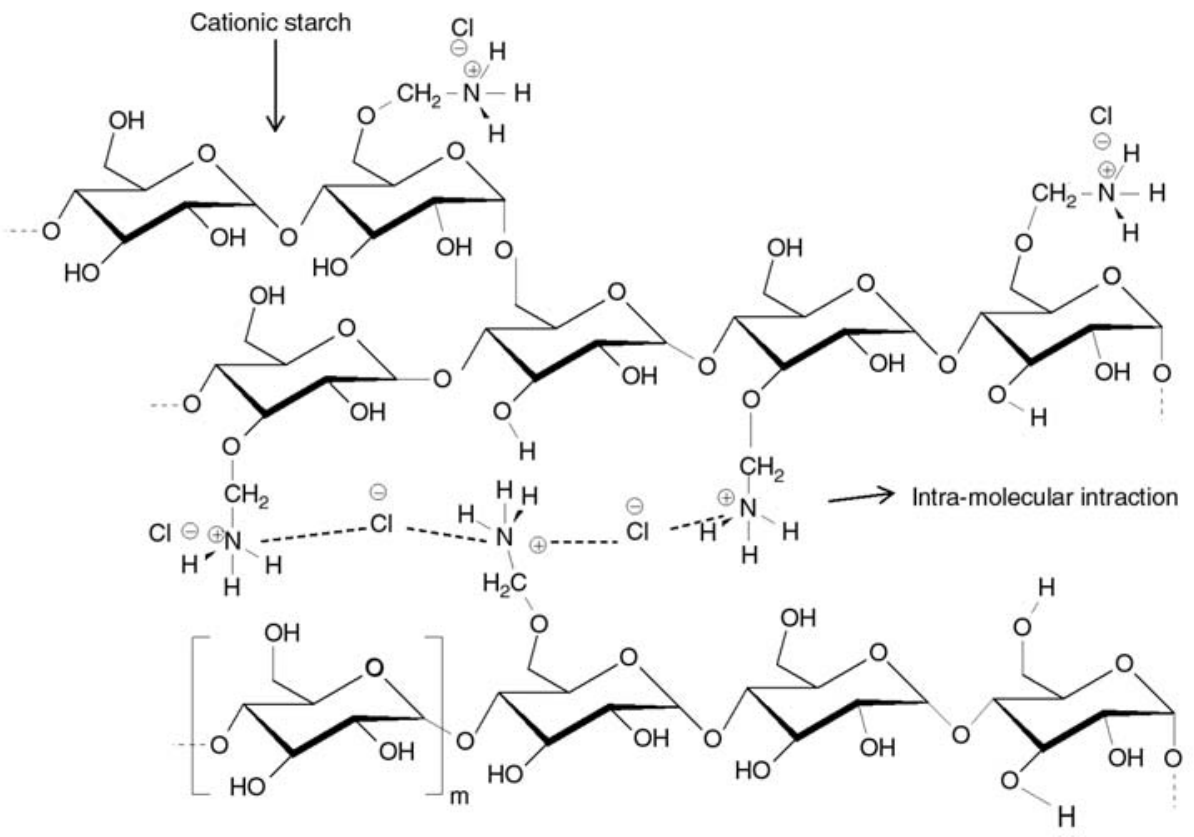

Figure 8. Possible interactions in cationic starch/PEO 


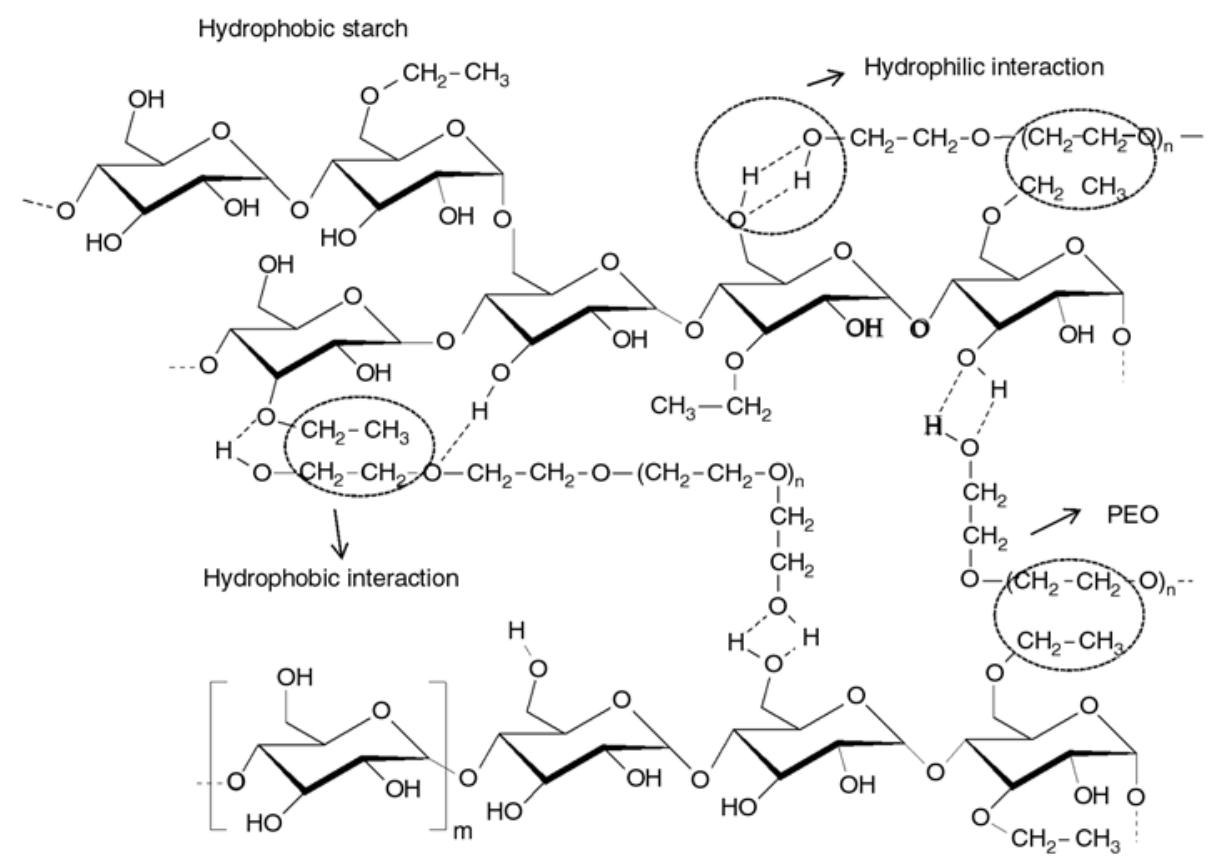

Figure 9. Possible interactions in hydrophobic starch/PEO

of water (ca. 78 at $20^{\circ} \mathrm{C}$ ) [56]. After the drying process, the mobility of the starch chains is not enough to allow conformational changes in order to interact with PEO leading to miscible system. Also, the cationic groups grafted onto starch present intra-molecular interactions destroying the $\mathrm{H}$-bonds between PEO and starch that it would probably occur if the starch was not modified.

Concerning blends with hydrophobic starch, the miscibility is understood as the synergy of two kinds of interactions, the hydrophilic H-bond interactions between hydroxyl groups of starch and oxygen atom of the ether group of PEO, and the hydrophobic interactions between the hydrophobic segments in the starch chain and the ethyl group present in the repeated units of PEO. The possible interactions between PEO and starches (unmodified, cationic and hydrophobic) are suggested in Figures 7-9.

\subsection{Spherulites growth rates}

The crystallization rates are dependent on the energy involved in the transport of the polymer chains towards to the growing crystals and also to the energy barrier for creation of secondary nuclei with a critical size [57]. These terms depend on the molecular characteristics of each component. For that reason, the crystallization rates become dependent on system-characterizing parameters, such as

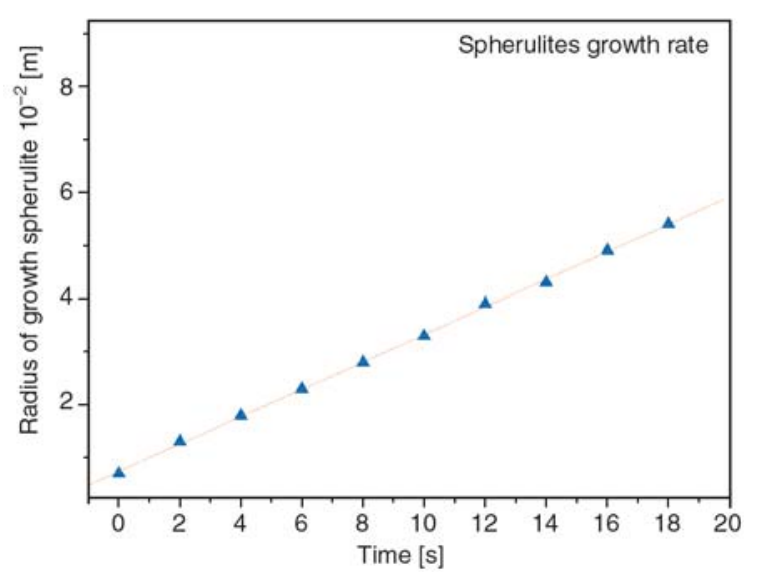

Figure 10. Dependence of isothermal radial growth rate of PEO as function of time (linear behavior)

$T_{C}, T_{g}, T_{m}$, and molar mass. The addition of a miscible amorphous component often causes the depression in the growth rate, owing the reduction of the melting temperature at equilibrium.

Figure 10 shows, in generic form, the time-dependent spherulite size at a defined $T_{C}$. The slope of the straight line is the spherulites growth rate for the respective blend ratio at a given $T_{C}$. It is important to notice that the isothermal spherulites growth presented linear dependence on time for all blend ratios.

When the radial growth rate for a given spherulite is plotted against the crystallization temperature $\left(T_{C}\right)$, a maximum is observed. The temperature dependence spherulite growth rate is understood in terms of two competing process, the rate of molec- 
ular transport in the melt (diffusion) which increases with temperature increasing, and the nucleation rate, which decreases with increasing temperature [57]. Diffusion is the prevailing factor at low temperatures, whereas at higher temperatures the nucleation rate is a dominant factor. When the $T_{C}$ is close to $T_{g}$, the macromolecular mobility is drastically reduced and, therefore, the crystallization become slower. If $T_{C}$ is close to $T_{m}$, it follows that the macromolecular mobility is high enough to avoid the crystallization and the nucleation rate would be extremely low [57].

Figure 11 refers to the dependence of the spherulites growth rate to the weight fraction of cationic starch at a given $T_{C}$. The spherulites growth rates in $\mathrm{PEO} /$ cationic starch remain almost invariable in the range from $80 / 20$ to $60 / 40$. However, for the ratios of 95/05 and 90/10, a considerable increase was observed in the spherulites growth rate, with respect to pure PEO. For instance, the spherulite growth rate for $95 / 05$ ratio rate was twice higher than that observed for the pure PEO. Besides, only the $95 / 05$ blend crystallizes at $59^{\circ} \mathrm{C}$. The spherulite growth rate in the $\mathrm{PEO} /$ cationic starch blends is higher than that of pure PEO (with the exception of $65 / 35$ and 60/40 ratios). This fact is another indicating that the blend ratios from $95 / 05$ to $70 / 30$ are immiscible, in agreement with the thermal analysis data. In this case, it may be inferred that cationic starch forms very small nucleus that would act as nucleation agents for the crystallization enhancing the spherulite growth rate.

Figure 12 refers to the dependence of the spherulites growth rate to the weight fraction of hydrophobic starch at a given $T_{C}$. In this case, the maximum

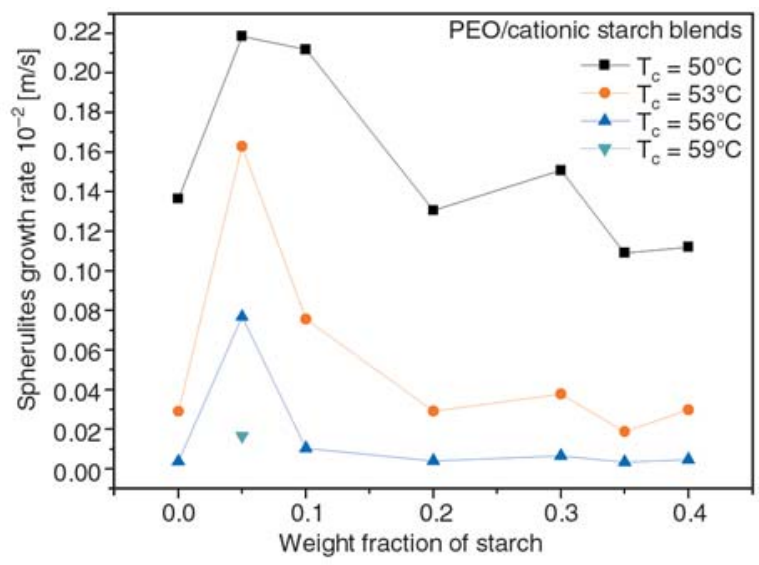

Figure 11. Spherulites growth rates as functions of weight fraction of starch for different ratios of $\mathrm{PEO} /$ cationic starch blends at a given $T_{C}$

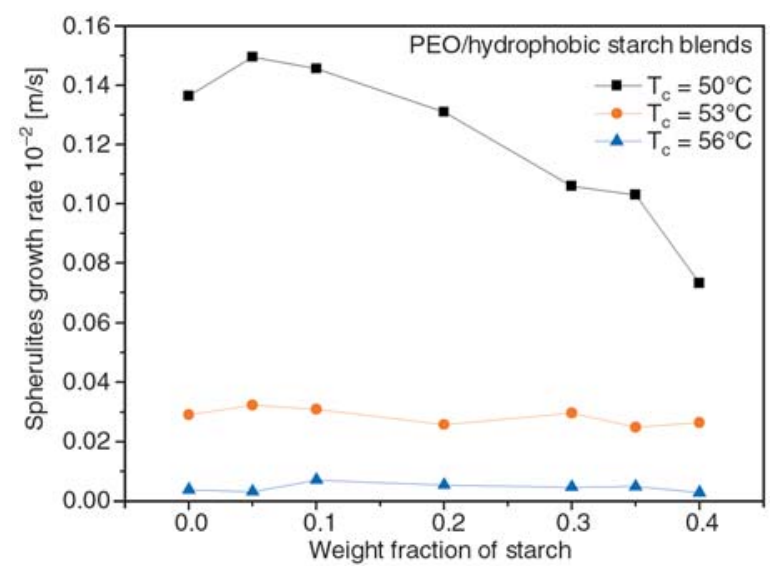

Figure 12. Spherulites growth rates as functions of weight fraction of starch for different ratios of PEO/hydrophobic starch blends at a given $T_{C}$

temperature in which the crystallization occurs was $56^{\circ} \mathrm{C}$, independent on blend ratio. It may be observed that the crystallization rates do not change significantly for all the blend ratios at 53 and $56^{\circ} \mathrm{C}$. Also, it was verified, for this system, a reduction in the crystallizations rates at $T_{C}=50^{\circ} \mathrm{C}$ with increasing amount of hydrophobic starch. At this temperature $\left(T_{C}=50^{\circ} \mathrm{C}\right)$, the spherulites growth rates of blends become practically equal to or lower than that of pure PEO. In the sense of the discussion above, the results would indicate polymer-polymer miscibility for PEO/hydrophobic starch. This would match with the results of miscibility from melting temperature depression analysis.

It should be emphasized that this kind of blends has great potential of application on the biomedical field, such as scaffolds for cell culture. The analyses of citotoxicity of those systems are in progress in our lab.

\section{Conclusions}

The miscibility and the spherulites growth rate in blends constituted by PEO and either cationic or hydrophobic starches were evaluated by using thermal analysis and optical microscopy. The PEO/ cationic system was considered to be immiscible, based on the positive value for the interaction parameter, $\chi_{12}$. This fact, in molecular level, was explained in terms of the solvent effect on the miscibility during the casting process. Also, the cationic groups grafted onto starch may present intramolecular interactions that would destroy the $\mathrm{H}$ bonds, between PEO and starch, that probably occur in PEO/unmodified starch. 
The hydrophobic starch was evaluated as miscible with the hydrophilic PEO, taking into account the negative value for interaction parameter, $\chi_{12}=$ -0.63 . It was pointed out that the small degree of substitution, the short hydrocarbon chain and the hydrophilic and hydrophobic interactions with PEO were responsible to the miscible behavior.

The understanding of the miscibility behavior of such systems (PEO/cationic starch and $\mathrm{PEO} /$ hydrophobic starch) maybe an interesting tool to evaluate the potential applications of those materials, mainly in the biomedical field such as scaffolds for cell culture.

\section{References}

[1] Sanchez I. C.: Bulk and interface thermodynamics of polymer alloys. Annual Review of Materials Science, 13, 387-412 (1983).

DOI: 10.1146/annurev.ms.13.080183.002131

[2] Utracki L. A.: Polymer alloys and blends: Thermodynamic and rheology. Hanser, Munich (1989).

[3] Hu Y., Sato H., Zhang J., Noda I., Ozaki Y.: Crystallization behavior of poly(l-lactic acid) affected by the addition of a small amount of poly(3-hydroxybutyrate). Polymer, 49, 4204-4210 (2008). DOI: 10.1016/j.polymer.2008.07.031

[4] Haddadine-Rahmoun N., Amrani F., Arighi V., Cowie J. M. G.: Interpolymer complexation and thermal behaviour of poly(styrene-co-maleic acid)/poly(vinyl pyrrolidone) mixtures. Thermochimica Acta, 475, 25-32 (2008).

DOI: $10.1016 / \mathrm{j} . \mathrm{tca} .2008 .06 .013$

[5] Reis K. C., Pereira J., Smith A. C., Carvalho C. W. P., Wellner N., Yakimets I.: Characterization of polyhydroxybutyrate-hydroxyvalerate (PHB-HV)/maize starch blend films. Journal of Food Engineering, 89, 361369 (2008).

DOI: 10.1016/j.jfoodeng.2008.04.022

[6] Pouteau C., Baumberger S., Cathala B., Dole P.: Lignin-polymer blends: Evaluation of compatibility by image analysis. Comptes Rendus Biologies, 327, 935-943 (2004).

DOI: 10.1016/j.crvi.2004.08.008

[7] Zeng M., Sun X., Wang Y., Yao X., Xiao H., Wang B., Qi C.: Correlations between the free-volume properties and the miscibility of chitosan/polar polymers blends membranes. Radiation Physics and Chemistry, 77, 1062-1068 (2008).

DOI: 10.1016/j.radphyschem.2008.01.008
[8] Girotto C., Cheyns D., Aernouts T., Banishoeib F., Lutsen L., Cleij T. J., Vanderzande D., Genoe J., Poortmans J., Heremans P.: Bulk heterojunction organic solar cells based on soluble poly(thienylene vinylene) derivatives. Organic Electronics, 9, 740 746 (2008). DOI: 10.1016/j.orgel.2008.05.014

[9] Moore J. A., Kaur S.: Blends of poly(amide-enaminonitrile) with poly(ethylene oxide), poly(4-vinylpyridine), and poly( $\mathrm{N}$-vinylpyrrolidone). Macromolecules, 31, 328-335 (1998).

DOI: $\underline{10.1021 / \mathrm{ma} 9701548}$

[10] Meier R. J.: Vibrational spectrosopy: A 'vanishing' discipline? Chemical Society Reviews, 34, 743-752 (2005).

DOI: $10.1039 / \mathrm{b} 503880 \mathrm{~d}$

[11] Stuart B. H.: A Fourier transform Raman spectroscopy study of the crystallisation behaviour of a poly(ether ether ketone)/poly(ether sulphone) blend. Spectrochimica Acta Part A: Molecular and Biomolecular Spectroscopy, 53, 107-110 (1997). DOI: $10.1016 /$ S1386-1425(97)83014-4

[12] Crispim E. G., Rubira A. F., Muniz E. C.: Solvent effects on the miscibility of PMMA/PVAc blends: II. Using two-dimensional NMR method, NOESY. Polymer, 41, 933-945 (2000). DOI: $\underline{10.1016 / \mathrm{S} 0032-3861(99) 00222-0}$

[13] Fadnis C., Illiger S. R., Rao K. P., Demappa T.: Miscibility studies of HPMC/PVA blends in water by viscosity, density, refractive index and ultrasonic velocity method. Carbohydrate Polymers, 74, 779-782 (2008). DOI: $\underline{10.1016 / j . c a r b p o l .2008 .04 .036}$

[14] Nishi T., Wang T. T.: Melting point depression and kinetic effects of cooling on crystallization in poly(vinylidene fluoride)-poly(methyl methacrylate) mixtures. Macromolecules, 8, 909-915 (1975). DOI: $10.1021 / \mathrm{ma} 60048 \mathrm{a} 040$

[15] García-Alonso A., Jiménez-Escrig A., Martin-Carrón N. M., Bravo L., Calixto F. S.: Assessment of some parameters involved in the gelatinization and retrogration of starch. Food Chemistry, 66, 181-187 (1999). DOI: $\underline{10.1016 / \mathrm{S} 0308-8146(98) 00261-1}$

[16] Singh J., Kaur L., McCarthy O. J.: Factors influencing the physico-chemical, morphological, thermal and rheological properties of some chemically modified starches for food applications-A review. Food Hydrocolloids, 21, 1-22 (2007).

DOI: $10.1016 /$ j.foodhyd.2006.02.006

[17] Scott G.: 'Green' polymers. Polymer Degradation and Stability, 68, 1-7 (2000). DOI: $\underline{10.1016 / S 0141-3910(99) 00182-2}$

[18] Wang X-L., Yang K-K., Wang Y-Z., Wang D-Y., Yang Z.: Crystallization and morphology of a novel biodegradable polymer system: Poly(1,4-dioxan-2one)/starch blends. Acta Materialia, 52, 4899-4905 (2004).

DOI: $\underline{10.1016 / j . a c t a m a t .2004 .06 .044}$ 
[19] Mano J. F., Sousa R. A., Boesel L. F., Neves N. M., Reis R. L.: Bioinert, biodegradable and injectable polymeric matrix composites for hard tissue replacement: State of the art and recent developments. Composites Science and Technology, 64, 789-817 (2004). DOI: $\underline{10.1016 / j . c o m p s c i t e c h .2003 .09 .001}$

[20] Vieira A. P., Ferreira P., Coelho J. F. J., Gil M. H.: Photocrosslinkable starch-based polymers for ophthalmologic drug delivery. International Journal of Biological Macromolecules, 43, 325-332 (2008).

DOI: $10.1016 /$ j.ijbiomac.2008.06.002

[21] Mehyar G. F., Liu Z., Han J. H.: Dynamics of antimicrobial hydrogels in physiological saline. Carbohydrate Polymers, 74, 92-98 (2008).

DOI: $\underline{10.1016 / \text { j.carbpol.2008.01.023 }}$

[22] Sadeghi M., Hoosseinzadeh H.: Synthesis of starchpoly(sodium acrylate-co-acrylamide) superabsorbent hydrogel with salt and $\mathrm{pH}$-responsiveness properties as a drug delivery system. Journal of Bioactive and Compatible Polymers, 23, 381-404 (2008). DOI: $10.1177 / 0883911508093504$

[23] Salgado A. J., Coutinho O. P., Reis R. L.: Novel starch-based scaffolds for bone tissue engineering: Cytotoxicity, cell culture, and protein expression. Tissue Engineering, 10, 465-474 (2004). DOI: $10.1089 / 107632704323061825$

[24] Mendes S. C., Reis R. L., Bovell Y. P., Cunha A. M., van Blitterswijk C. A., Bruijn J. D.: Biocompatibility testing of novel starch-based materials with potential application in orthopaedic surgery: A preliminary study. Biomaterials, 22, 2057-2064 (2001). DOI: $10.1016 / \mathrm{S} 0142-9612(00) 00395-1$

[25] Sohara A. K., Parmod K., Kansal P., Shishir S.: Effect of cationic starch and long fibered bamboo pulp on the double fold of recycled bagasse paper. Quarterly Journal of Indian Pulp and Paper Technical Journal, 20, 179-184 (2008).

[26] Packhan D. E.: Adhesive technology and sustainability. International Journal of Adhesion and Adhesives, 29, 248-252 (2009).

DOI: $10.1016 /$ j.ijadhadh.2008.06.002

[27] Mano J. F., Reis R. L.: Viscoelastic monitoring of starch-based biomaterials in simulated physiological conditions. Materials Science and Engineering A, 370, 321-325 (2004).

DOI: $10.1016 /$ j.msea.2003.08.088

[28] Liao H. T., Wu C. S.: Preparation and characterization of ternary blends composed of polylactide, $\operatorname{poly}(\varepsilon-$ caprolactone) and starch. Materials Science and Engineering: A, 515, 207-214 (2009).

DOI: $10.1016 /$ j.msea.2009.03.003

[29] Wu R-L., Wang X-L., Li F., Li H-Z., Wang Y-Z.: Green composite films prepared from cellulose, starch and lignin in room-temperature ionic liquid. Bioresource Technology, 100, 2569-2574 (2009).

DOI: $10.1016 /$ j.biortech.2008.11.044
[30] Mano J. F., Koniarova D., Reis R. L.: Thermal properties of thermoplastic starch/synthetic polymer blends with potential biomedical applicability. Journal of Materials Science: Materials in Medicine, 14, 127 135 (2003).

DOI: 10.1023/A:1022015712170

[31] Hoffmann B., Volkmer E., Kokott A., Weber M., Hamisch S., Schieker M., Mutschler W., Ziegler G.: A new biodegradable bone wax substitute with the potential to be used as a bone filling material. Journal of Materials Chemistry, 17, 4028--4033 (2007).

DOI: $10.1039 / \mathrm{b} 707992 \mathrm{n}$

[32] Lee K. Y., Yuk S. H.: Polymeric protein delivery systems. Progress in Polymer Science, 32, 669-697 (2007).

DOI: 10.1016/j.progpolymsci.2007.04.001

[33] Nagata M., Yamamoto Y.: Photoreversible poly(ethylene glycol)s with pendent coumarin group and their hydrogels. Reactive and Functional Polymers, 68, 915-921 (2008).

DOI: $10.1016 /$ j.reactfunctpolym.2008.01.003

[34] Salmaso S., Semenzato A., Bersani S., Matricardi P., Rossi F., Caliceti P.: Cyclodextrin/PEG based hydrogels for multi-drug delivery. International Journal of Pharmaceutics, 345, 42-50 (2007). DOI: 10.1016/j.ijpharm.2007.05.035

[35] Kuo Y-C., Ku I-N.: Cartilage regeneration by novel polyethylene oxide/chitin/chitosan scaffolds. Biomacromolecules, 9, 2662-2669 (2008). DOI: $\underline{10.1021 / \mathrm{bm} 800651 \mathrm{r}}$

[36] Reignier J., Huneault M. A.: Preparation of interconnected poly( $\varepsilon$-caprolactone) porous scaffolds by a combination of polymer and salt particulate leaching. Polymer, 47, 4703-4717 (2006).

DOI: 10.1016/j.polymer.2006.04.029

[37] Hou Q., Grijpma D. W., Feijen J.: Porous polymeric structures for tissue engineering prepared by a coagulation, compression moulding and salt leaching technique. Biomaterials, 24, 1937-1947 (2003).

DOI: 10.1016/S0142-9612(02)00562-8

[38] Bozukova D., Pagnoulle C., Pauw-Gillet M. C., Desbief S., Lazzaroni R., Ruth N., Jérome R., Jérome C.: Improved performances of intraocular lenses by poly(ethylene glycol) chemical coatings. Biomacromolecules, 8, 2379-2383 (2007).

DOI: $10.1021 / \mathrm{bm} 0701649$

[39] Chen H., Zhang Z., Chen Y., Brook M. A., Sheardown H.: Protein repellant silicone surfaces by covalent immobilization of poly(ethylene oxide). Biomaterials, 26, 2391-2399 (2005).

DOI: $10.1016 /$ j.biomaterials.2004.07.068

[40] Unsworth L. D. Sheardown H., Brash J. L.: Polyethylene oxide surfaces of variable chain density by chemisorption of PEO-thiol on gold: Adsorption of proteins from plasma studied by radiolabelling and immunoblotting. Biomaterials, 26, 5927-5933 (2005). DOI: $\underline{10.1016 / \text { j.biomaterials.2005.03.010 }}$ 
[41] Archambault J. G., Brash J. L.: Protein repellent polyurethane-urea surfaces by chemical grafting of hydroxyl-terminated poly(ethylene oxide): Effects of protein size and charge. Colloids and Surfaces B: Biointerfaces, 33, 111-120 (2004).

DOI: $10.1016 /$ j.colsurfb.2003.09.004

[42] Willerth S. M., Sakiyama-Elbert S. E.: Approaches to neural tissue engineering using scaffolds for drug delivery. Advanced Drug Delivery Reviews, 59, 325338 (2007).

DOI: 10.1016/j.addr.2007.03.014

[43] Popelka Š., Machová L., Rypácek F.: Adsorption of poly(ethylene oxide)-block-polylactide copolymers on polylactide as studied by ATR-FTIR spectroscopy. Journal of Colloid and Interface Science, 308, 291299 (2007).

DOI: $\underline{10.1016 / j . j c i s .2006 .12 .022}$

[44] Deitzel J. M., Keinmeyer J. D., Hirnonen J. K., Tan N. C. B.: Controlled deposition of electrospun poly(ethylene oxide) fibers. Polymer, 42, 8163-8170 (2001). DOI: $10.1016 / \mathrm{S} 0032-3861(01) 00336-6$

[45] Hoffman J. D., Weeks J. J.: Melting process and the equilibrium melting temperature of polychlorotrifluoroethylene. Journal of Research of the National Bureau of Standards Section A: Physics and Chemistry, 66, 13-28 (1962).

[46] Pereira A. G. B., Gouveia R. F., de Carvalho G. M., Rubira A. F., Muniz E. C.: Polymer blends based on PEO and starch: Miscibility and spherulite growth rate evaluated through DSC and optical microscopy. Materials Science and Engineering: C, 29, 499-504 (2009). DOI: $\underline{10.1016 / \text { j.msec.2008.09.009 }}$

[47] Wang P-X., Wu X-L., Hua X-D., Kun X., Ying T., Bing D-X., Bo L-W.: Preparation and characterization of cationic corn starch with a high degree of substitution in dioxane-THF-water media. Carbohydrate Research, 344, 851-855 (2009). DOI: $\underline{\text { 10.1016/j.carres.2009.02.023 }}$
[48] Baek K., Yang J. S., Kwon T. S., Yang J. W.: Cationic starch-enhanced ultrafiltration for $\mathrm{Cr}(\mathrm{VI})$ removal. Desalination, 206, 245-250 (2007).

DOI: $10.1016 /$ j.desal.2006.03.568

[49] Qiao L., Gu Q-M., Cheng H. N.: Enzyme-catalyzed synthesis of hydrophobically modified starch. Carbohydrate Polymers, 66, 135-140 (2006). DOI: $10.1016 /$ j.carbpol.2006.02.033

[50] Coleman M. M., Painter P. C.: Hydrogen bonded polymer blends. Progress in Polymer Science, 20, 1-59 (1995).

DOI: 10.1016/0079-6700(94)00038-4

[51] Rim P. B., Runt J. P.: Melting point depression in crystalline/compatible polymer blends. Macromolecules, 17, 1520-1526 (1984).

DOI: $10.1021 / \mathrm{ma} 00138 \mathrm{a} 017$

[52] Mark J. E.: Polymer data handbook. Oxford University Press, New York (1999).

[53] Chow T. S.: Miscible blends and block copolymers. Crystallization, melting and interaction. Macromolecules, 23, 333-337 (1990).

DOI: $10.1021 / \mathrm{ma} 00203 \mathrm{a} 057$

[54] Alfonso G. C., Russell T. P.: Kinetics of crystallization in semicrystalline/amorphous polymer mixtures. Macromolecules, 19, 1143-1152 (1986). DOI: $10.1021 / \mathrm{ma} 00158 \mathrm{a} 036$

[55] Crispim E. G., Rubira A. F., Muniz E. C.: Solvent effects on the miscibility of poly(methyl methacrylate)/poly(vinyl acetate) blends: I: Using differential scanning calorimetry and viscometry techniques. Polymer, 40, 5129-5135 (1999). DOI: $\underline{10.1016 / \mathrm{S} 0032-3861(98) 00653-3}$

[56] Cabane B., Vuilleumier R.: The physics of liquid water. Comptes Rendus Geoscience, 337, 159-171 (2005). DOI: $\underline{10.1016 / j . c r t e .2004 .09 .018}$

[57] Sperling L. H.: Introduction to physical polymer science. Wiley, Bethlehem (2006). 